\title{
Performance Analysis of Single Phase Bi-Directional Converter Using CSPWM and Sinusoidal-PWM Techniques for Enhancement in Power Factor and Voltage Regulation
}

\author{
R.G. Mapari \\ Department of electronics, SGBA University, Amravati \\ India
}

\begin{abstract}
This paper present a performance analysis of bi-directional converter using continuous switching pulse width modulation (CSPWM) and sinusoidal pulse width modulation (S-PWM) techniques. The analysis is carried out by means of rectification and inversion operation using two cases. In CASE-I CSPWM technique is used for the rectification operation and S-PWM is for inversion operation. And in CASE-II both the rectification and inversion are implemented using S-PWM technique. Both the modulation techniques are digitally implemented and the optimized parameters are achieved without current control loop. The analysis is based on the optimization of parameters like power factor, voltage regulation, harmonic distortion and bi-directional operation. These converter topologies are evaluated on the basis of silent features like partial digital implementation, low cost, simple and high performance to analyse its applicability. The proposed converter is bridgeless and transformer-less which highlights its high efficiency, high power factor and low harmonic distortions for the CASE-I.
\end{abstract}

Keywords-Power factor correction (PFC) converters; continuous switching pulse width modulation (CSPWM); sinusoidal pulse width modulation (SPWM); AC-DC-AC converters; voltage regulation

\section{INTRODUCTION}

Conventionally, ac-dc converters, which are also called rectifiers, are developed using diodes and thyristors to provide controlled and uncontrolled dc power with unidirectional and bidirectional power flow [1]. They have the demerits of poor power quality in terms of injected current harmonics, caused voltage distortion and poor power factor at input $\mathrm{AC}$ mains and slow varying rippled DC output at load end, low efficiency and large size of ac and dc filters [2].

Generally, the control structure of a three- phase six switch PWM boost converter consist of an inner current control loop and outer voltage control loop [3]. The current controller senses the input current and compares it with a sinusoidal current reference. To obtain the current reference, the phase information of the utility voltage or current is required. This information is obtained by employing a phase lock loop (PLL), which creates transients if the frequency ratio changes [4]. To simplify the control structure, one-cycle-control (OCC) based

\author{
D. Wakde \\ Director, P.R. Patil COE, Amravati, Maharashtra \\ India
}

AC-to-DC converter has been proposed [5-7]. However, the scheme based on OCC exhibit instability in operation when magnitude of the load current falls below a certain level or when the converter is operating in the inverting mode of operation. To avoid it a modified OCC Bi-directional high power factor AC-to-DC converter is proposed in [8]. This scheme uses saw-tooth wave to generate PWM pulses which incorporate low frequency harmonics. OCC presents some drawbacks intrinsic with its physical realization: the controller and its parameters can not be modified without hardware re-design; moreover they are influenced by temperature drifts, typical of analog systems.

A new single phase multilevel flying capacitor active rectifier using hysteresis based control is reported in [9], the power factor and output voltage regulation is achieved by controlling the input current. PLL is used to find the phase information of input voltage which creates the transients as the frequency ratio changes. Smart charger for electrical vehicle using three wire distribution feeders is proposed in [10]. To achieve bi-directional flow six active switches are used, which increases switching losses, hardware and complexity.

This paper not only presents the comparative study between two cases but addresses the aforementioned drawbacks. The used converter is bridgeless, transformer-less and output DC current sensor less. All the above mentioned schemes are implemented digitally to incorporate the advantages of digital implementation. The detail simulation is carried out using MATLAB/Simulink and to validate it experimental setup is develop using DSPic33FJ64MC802 digital controller for $1 \mathrm{KW}$ system.

\section{SYSTEM MODELING}

To understand the principle of single phase bi-directional converter to achieve high power factor in both the directions (from source to load and load to the source) and output DC link voltage regulation a simple converter is explained shown in Fig. 1. VIN and Iin are line voltage and line current respectively. For any change in load, load current IL varies due to this change input current Iin varies which affects on power factor. To 
compensate it average fundamental voltage VAB is adjusted using Pulse Width Modulation (PWM) technique.

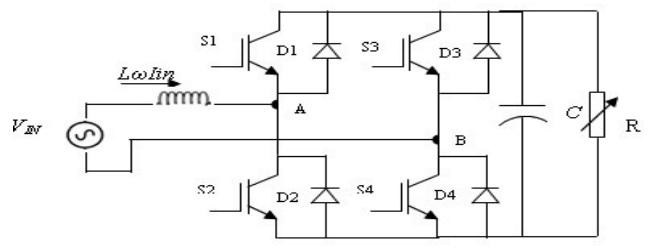

FIGURE I. SINGLE-PHASE FULL BRIDGE CONVERTER.

\subsection{Control block for single phase converter}

Fig. 2 (a) shows the control block for single phase converter to achieve the high power factor, DC voltage regulation, bi-directional power flow and reduced current harmonics. VO* is the reference output voltage that we want to achieve. The actual feedback voltage $\mathrm{VO}$ is compared with the reference voltage VO*. The output of the comparator is the difference between them we called it is error; this difference is then fed to the voltage controller in order to take the action against it. Because any change in output capacitor voltage VO as shown in Fig. 1 due to change in load there is change in load current and we know in ideal case for $100 \%$ efficiency output power is equal to input power as shown below:

VINpeak x Iinpeak $=$ Vo $x$ IL.

$V_{I N-p e a k}$ and $I_{\text {inpeak }}$ are peak values of input voltage and input current. As $I_{L}$ changes, the product $(F \propto \times I L)$ change so to compensate it peak value Iin necessary to change hence output of controller is Iin* that is required reference input current. This Iin* flowing through inductor. The actual input current Iin is sensed and compared with the reference input current Iin*. The difference between them is fed to the current controller. The current controller is adjusted such that for any change in input current Iin, it adjust the average fundamental voltage $\operatorname{Vr}(\mathrm{VAB})$. Hence output of controller is reference average fundamental voltage $\mathrm{Vr}^{*}$ and is fed to the PWM converter. This reference fundamental voltage is acts as a modulating signal to the PWM converter. The carrier frequency is chosen so high that PWM converters action becomes faster, so that Iin and Iin* remains sinusoidal and unchanged. Also Iin and $V_{I N}$ both are sinusoidal and in phase to get high power factor. From Fig. 1 the input side representation of the single phase converter circuit is shown in Fig. 2 (b). From this we can find the actual input current Iin. By applying KVL, we can write the equation as below:

$$
V I N+L \frac{d t r z}{d t}=V r
$$

For the line current the equation can be modified as:

$$
I_{x}=\frac{1}{L} \int(V x-V I N) d t
$$

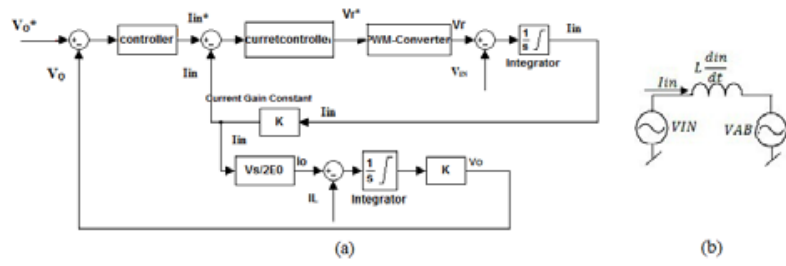

FIGURE II. (A) CONTROL BLOCK FOR SINGLE PHASE CONVERTER AND (B) INPUT SIDE REPRESENTATION OF THE SINGLE PHASE CONVERTER CIRCUIT.

\section{SIMULATED AND EXPERIMENTAL RESULTS}

In order to check the performance of converter using CSPWM and SPWM techniques for rectification and inversion using SPWM technique detail simulation is carried out on MATLAB/Simulink platform and the DSPic33FJ64MC802 digital controller is used for the implementation. The parameters selected for the simulation and implementation are listed in Table 1 . The output DC voltage $300 \mathrm{~V}$ keeping constant and the DC side load changed from $1 \mathrm{KW}$ to $400 \mathrm{~W}$. The experimental waveforms are adjusted on screen using divider network for clear visualization.

TABLE I. PARAMETER VALUES FOR SIMULATION AND IMPLEMENTATION.

\begin{tabular}{|l|l|l|}
\hline Parameter & SYMBOL & Value \\
\hline Line RMS voltage & VIN & $140 \mathrm{~V}$ \\
\hline Boosted DC voltage & $\mathrm{VO}$ & $300 \mathrm{~V}$ \\
\hline Switching frequency & $\mathrm{fs}$ & $20 \mathrm{KHz}$ \\
\hline Line frequency & $\mathrm{f}$ & $50 \mathrm{~Hz}$ \\
\hline DC link capacitor & $\mathrm{C}$ & $440 \mu \mathrm{F}$ \\
\hline Input inductor & $\mathrm{L}$ & $1 \mathrm{mH}$ \\
\hline Load resistance & $\mathrm{R}$ & $(90 \Omega$ \\
& & $225 \Omega)$ \\
\hline Triangular period & $\mathrm{Tr}$ & $50 \mu \mathrm{sec}$ \\
\hline Controller current gain & $\mathrm{Ki}$ & 9 \\
\hline Converter gain & $\mathrm{G}$ & 40 \\
\hline
\end{tabular}

A. Simulated And Experimental Results Of Rectification Using CSPWM

Simulated and experimental result waveforms for rectifying mode of operation are shown in Fig. 3. Trace 1 of Fig. 3a shows the simulated waveform of line current following the line voltage to indicate the unity power factor. The experimental result for the same is shown in Trace 2 of Fig. 3a. This shows the exactly similar result like simulated waveform. The channel 1 is at 50V/Div and channel 3 is at $5 \mathrm{Amp} / \mathrm{Div}$.

The DC side load is changed from $5 \%$ to $80 \%$ periodically to show the output voltage regulation which is shown in Fig. $3 \mathrm{~b}$. Trace 1 of Fig. $3 \mathrm{~b}$ shows simulated result, it can be seen that as load changes from $80 \%$ to $5 \%$ and from $5 \%$ to $80 \%$ the DC link voltage remains regulated. Trace 2 shows experimental result for the same. It can be observed that the DC link voltage regulated within very small period which is negligible when load change occurred. Channel 2 and 4 are at 50V/Div and 
channel 3 is at $2 \mathrm{Amp} / \mathrm{Div}$. Trace 3 visualizes the step change and period of DC link voltage regulation after load change occurred. When load changes from $5 \%$ to $80 \%$, time/division knob is at $250 \mathrm{msec}$ which shows the voltage regulated within the period of $40 \mathrm{msec}$, the line current increases and line voltage remains constant. The line current harmonics pattern is show in Fig. 3c. It can be observed that all the lower order harmonics and 3rd harmonics are totally discarded while 5th and 7th harmonics are reduces up to negligible level.

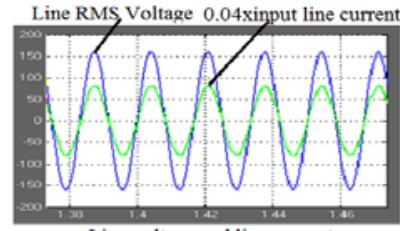

Line voltage and line current
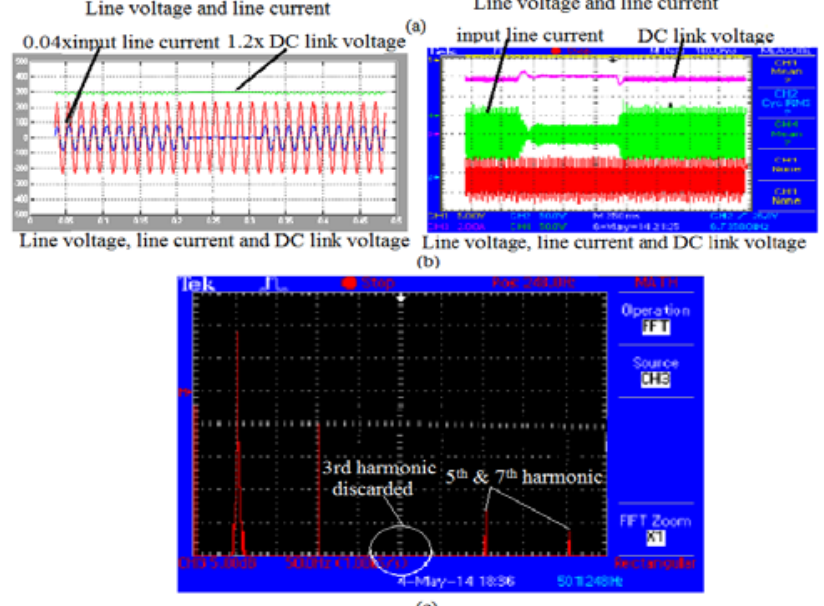

(c)

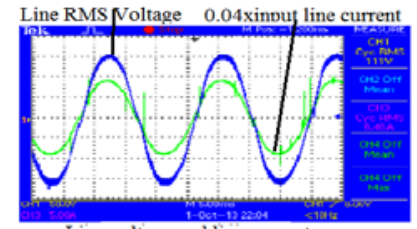

Line voltage and line current
FIGURE III. (A) SIMULATED AND EXPERIMENTAL RESULTS OF LINE CURRENT AND LINE VOLTAGE TO SHOW HIGH POWER FACTOR. (B) SIMULATED AND EXPERIMENTAL RESULTS OF LINE VOLTAGE, LINE CURRENT AND DC LINK VOLTAGE WHEN LOAD CHANGES FROM $80 \%$ TO 5\% PERIODICALLY TO SHOW VOLTAGE

STABILIZATION PERIOD OF 40MSEC. (C) LINE CURRENT HARMONIC PATTERN TO SHOW 3RD HARMONICS DISCARDED AND REDUCTION IN 5TH AND 7TH HARMONICS.

\section{B. Simulated And Experimental Results Of Rectification Using SPWM}

Simulated and experimental result waveforms for rectifying mode of operation are shown in Fig. 4. Trace 1 of Fig. 4a shows the simulated waveform of line current flowing maximum at the peak of line voltage and almost zero at the starting to indicate the degradation in power factor. The experimental result for the same is shown in Trace 2 of Fig. 4a. This shows the exactly similar result like simulated waveform. The channel 1 is at $50 \mathrm{~V} / \mathrm{Div}$ and channel 3 is at 5Amp/Div.

The DC side load is changed from $5 \%$ to $80 \%$ periodically to show the output voltage regulation which is shown in Fig. 4b. Trace 1 of Fig. $4 \mathrm{~b}$ shows simulated result. It shows that when load changes from $5 \%$ to $80 \%$ the voltage regulated within the period of $100 \mathrm{msec}$, also the line current and line voltage disturbance increases. The line current harmonics pattern is show in Fig. 4c.

\section{Simulated And Experimental Results Of Inversion Using SPWM}

To show the bi-directional operation using the same converter the inversion operation is shown in Fig. 5. The simulated result in Fig. 5a shows the inverted current is exactly $180 \mathrm{o}$ of inverted voltage. The experimental results are taken for pure resistive load shown in Fig. 5 b.

\section{Parametric Study Between Proposed CASES}

The comparisons between the two CASES are made for various loads ranging from $90 \Omega$ to $250 \Omega$. The parameters observed during the comparison are power factor, THD and DC load current. The detail graphical representation is shown in Fig. $6 \mathrm{a}$ and $6 \mathrm{~b}$. Figure $6 \mathrm{a}$ shows the parameters for the CASE-I (rectification using CSPWM and inversion using SPWM). It can be observed that full load power factor is $97.8 \%$ and THD is $6.3 \%$ only. The parameters for the CASE-II (rectification and inversion both using SPWM) are shown in Fig. 6b. It is shown that power factor is $80.3 \%$ and THD is $19.8 \%$.

\section{CONCLUSION}

Two schemes CSPWM and SPWM are reported for the same converter for rectification and inversion operation. The scheme using rectification with CSPWM and inversion with SPWM exhibit remarkable advantages such as high power factor, less DC link voltage stabilization period and low THDs. Compare to this scheme second scheme (rectification and inversion both using SPWM) is less efficient. The detail simulation studies are carried out to show the comparison and effectiveness of the schemes. The feasibility of the schemes is confirmed through the detail experimental studies.
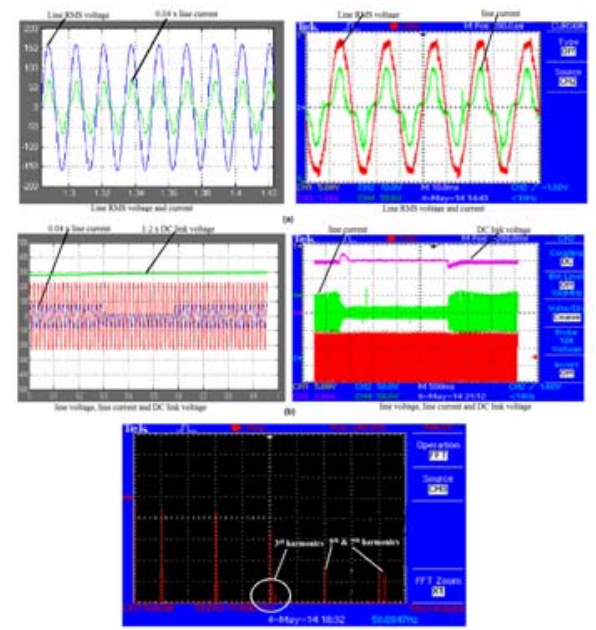

FIGURE IV. (A) SIMULATED AND EXPERIMENTAL RESULTS OF LINE CURRENT AND LINE VOLTAGE TO SHOW DEGRADED POWER FACTOR. (B) SIMULATED AND EXPERIMENTAL RESULTS OF LINE VOLTAGE, LINE CURRENT AND DC LINK VOLTAGE WHEN LOAD

CHANGES FROM $80 \%$ TO 5\% PERIODICALLY TO SHOW DISTORTIONS DURING VOLTAGE STABILIZATION AND STABILIZATION PERIOD OF 100MSEC. (C) LINE CURRENT HARMONICS PATTERN TO SHOW 3RD, 5TH AND 7TH HARMONICS ARE PRESENT 


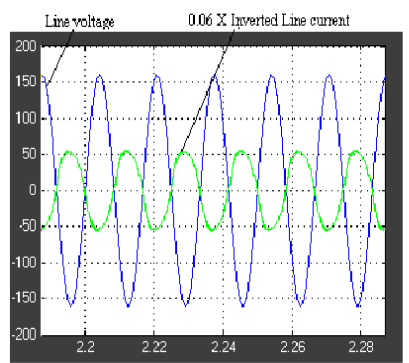

Inverted Line voltage and line current

(a)

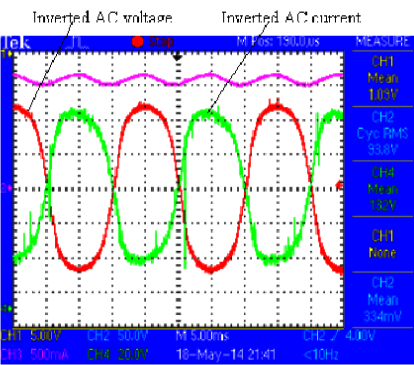

Inverted $\mathrm{AC}$ woltage and current

(b)

FIGURE V. (A) SIMULATED RESULTS OF INVERTED LINE CURRENT AND LINE VOLTAGE AT EXACTLY 180O PHASE SHIFTED TO SHOW INVERSION ACTION, (B) EXPERIMENTAL RESULTS.

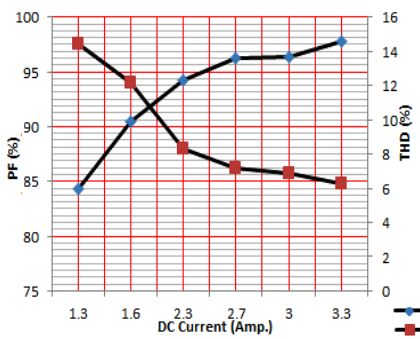

(a)

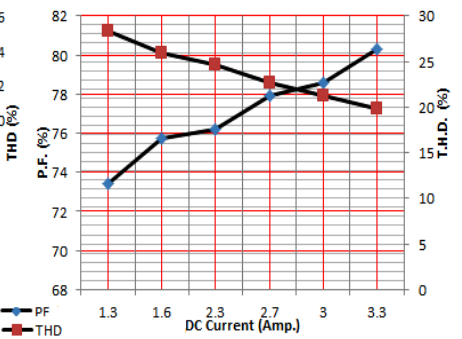

(b)

FIGURE VI. (A) VARIATION IN POWER FACTOR AND THD WITH CHANGE IN LOAD AND DC LOAD CURRENT FOR CASE-I (B) VARIATION IN POWER FACTOR AND THD WITH CHANGE IN LOAD AND DC LOAD CURRENT FOR CASE-II.

\section{REFERENCES}

[1] W. M. Grady, M. J. Samotyj, and A. H. Noyola, Survey of active power line conditioning methodologies, IEEE Trans. Power Delivery, 5, pp.1536-1542, 1990 .

[2] Bhim Singh, Brij N. Singh, Ambrish Chandra \& Ashish Pandey, A Review of Single-Phase Improved Power Quality AC-DC Converters. IEEE Trans. Industrial Elect. 50(5), 2003.

[3] D. C. Lee and D. S. Lim, AC voltage and current sensorless control of three-phase PWM rectifiers, IEEE Trans. Power Electron. 17(6), Nov. 2002.

[4] Heinz Willi, Hans-Christoph, Georg Victor, Analysis and Realization of a Pulsewidth Modulator Based on Voltage Space Vector, IEEE Trans. on Ind. Applications, 24(1), Jan-Feb 1988.

[5] M. K. Smedley and S. Cuk, One cycle control of power converters, IEEE Trans. Power Electron. 10, pp. 475-481, Nov. 1995.

[6] C. Yang and K. M. Smedley, One-cycle-controlled three-phase grid connected inverters and their parallel operation. IEEE Trans. Ind.Applicat., 44(2), pp. 129-136, Mar. /Apr. 2008.

[7] C. Yang and K. M. Smedley, Parallel operation of one-cycle controlled three-phase PFC rectifiers, IEEE Trans. Ind. electron, 54(6), pp. 745-752, Dec. 2007.

[8] Dharmraj Ghodke, Kishor Chattarjee, Modified One Cycle Controlled Bidirectional High-Power-Factor AC-to-DC Converter, IEEE trans. Ind. Electron., 55(6), pp. 1203-1210, August 2008.

[9] M. Khazraei, H. Sepahvand, M. Ferdowsi, K.A. Corzine, Hysteresis-Based Control of a Single-Phase Multilevel Flying Capacitor Active Rectifier, IEEE trans. Power Elect. 28(1), pp. 154-164, 2013.

[10] T. Tanaka, T. Sekiya, M. Okamoto, E. Hiraki, Smart Charger for Electric vehicles with Power-Quality compensator on Single-Phase three wire Distribution Feeders, IEEE trans. Power delivery, 49(6), pp. 2628-2635, 2013. 